\title{
Avoiding Potential Medication Errors Associated with Non-intuitive Medication Abbreviations
}

\author{
Jonas Shultz, Lisa Strosher, Shaheen Nenshi Nathoo, and Jim Manley
}

\begin{abstract}
Background: Pharmaceutical companies use a variety of abbreviations to denote short- and long-acting medications. Errors involving the administration of these medications are frequently reported.

Objectives: To evaluate comprehension rates for abbreviations used to denote short- and long-acting medications and to evaluate whether changes to medication labels could reduce potential errors in the selection and administration of medications.
\end{abstract}

Methods: In phase 1 of the study, nursing staff were asked to define 4 abbreviations and then to categorize them by release rate. In phase 2, a simulation exercise, nursing staff were asked if it would be appropriate to administer a medication illustrated in a photograph (oxycodone CR 5-mg blister pack) on the basis of information highlighted in a screen shot of an electronic medication administration record (order for oxycodone $5 \mathrm{mg}$ ). Three different presentations were used to identify the medication in the medication administration record and on the drug label.

Results: In phase 1, 10 (28\%) of 36 nursing staff members knew what all 4 abbreviations meant, and 14 (39\%) correctly classified all 4 abbreviations as indicating a short- or a long-acting medication. In the simulation exercise (phase 2), labelling changes reduced the likelihood of a potential medication administration error.

Conclusions: Most abbreviations used to indicate short- versus longacting medications were not correctly understood by study participants. Of more concern was the incorrect interpretation of some abbreviations as indicating the opposite release rate (e.g., "ER" interpreted as meaning "emergency release", rather than "extended release", with incorrect classification as a short-acting medication). This evaluation highlighted the potential consequences of using non-intuitive abbreviations to differentiate high-risk medications having different release rates.

Key words: medication abbreviations, release rate, medication error, human factors

\section{RÉSUMÉ}

Contexte : Les sociétés pharmaceutiques utilisent une panoplie d'abréviations pour désigner leurs médicaments à action brève ou prolongée. Or, on signale des erreurs fréquentes d'administration de ces médicaments.

Objectifs : Évaluer le taux de compréhension des abréviations utilisées pour désigner les médicaments à action brève et à action prolongée et si des changements aux étiquettes de ces médicaments pourraient réduire les erreurs potentielles dans le choix et l'administration de ceux-ci.

Méthodes : Dans la 1re phase de l'étude, on a demandé au personnel infirmier de définir quatre abréviations et de les classer par vitesse de libération. Dans la 2e phase, un exercice de simulation, on a demandé au personnel infirmier s'il serait approprié d'administrer le médicament qu'on leur présentait sur une photo (oxycodone $C R$ [controlled release, c.-à-d. à libération contrôlée] à $5 \mathrm{mg}$ en plaquettes alvéolées) en tenant compte de l'information surlignée dans une capture d'écran d'un registre électronique d'administration des médicaments (prescription d'oxycodone $5 \mathrm{mg}$ ). Trois présentations différentes ont été utilisées pour désigner le médicament dans le registre d'administration des médicaments et sur l'étiquette du médicament.

Résultats : Dans la $1^{\text {re }}$ phase de l'étude, 10 (28\%) des 36 membres du personnel infirmier connaissaient la signification des quatre abréviations et $14(39 \%)$ les ont correctement classées dans la catégorie action brève ou action prolongée. Dans l'exercice de simulation (2 ${ }^{\circ}$ phase), les changements à l'étiquette ont réduit la possibilité d'une erreur potentielle d'administration du médicament.

Conclusions : La plupart des abréviations utilisées pour désigner les médicaments à action brève par rapport à ceux à action prolongée n'étaient pas bien comprises du personnel infirmier. Mais plus inquiétante était l'interprétation erronée de certaines abréviations à l'inverse de leur vitesse de libération (p. ex., ER interprétée comme étant emergency release (c.-à-d. à libération d'urgence) plutôt que extended release (c.-à-d. à libération prolongée) et incorrectement classée comme un médicament à action brève). Cette évaluation souligne les conséquences potentielles de l'utilisation d'abréviations non intuitives pour différencier les médicaments à risque élevé ayant des vitesses de libération différentes.

Mots clés : abréviations des médicaments, vitesse de libération, erreurs de médication, facteurs humains

[Traduction par l'éditeur] 


\section{INTRODUCTION}

$\mathrm{P}$ harmaceutical companies use a variety of abbreviations to denote short- and long-acting medications. Commonly used abbreviations include CR for "controlled release", SR for "sustained release", ER for "extended release", and IR for "immediate release". In an analysis of medication pairs in which the wrong drug was administered, oxycodone (short-acting) and oxycodone CR (long-acting) constituted the third most frequent pair. ${ }^{1}$

Confusion about short- and long-acting medications is not new. In 1989, the US Institute for Safe Medication Practices (ISMP) attempted to convince the US Food and Drug Administration (FDA) of the need to standardize these drug name suffixes. ${ }^{2}$ Unfortunately, the FDA still offers no guidance to pharmaceutical companies regarding appropriate denotations of drug release rates. ${ }^{3}$ Numerous reports of confusion between short- and long-acting medications have been published by the ISMP (US) ${ }^{4-7}$ and by the Institute for Safe Medication Practices Canada (ISMP Canada). ${ }^{8,9}$ The lack of standardized abbreviations, communication of drug names without suffixes, use of similar packaging, overlap in dosages between products with different designations, and adjacent storage of products with the same product name but different designations have been identified as contributing factors. ${ }^{10}$ Avoiding the use of potentially confusing abbreviations and spelling out the release rate (e.g., "CONTROLLED RELEASE") are among the many frequently suggested recommendations to reduce confusion. ${ }^{8,11,12}$

Little is known about the efficacy of these recommendations or whether certain abbreviations are more intuitive than others. To further elucidate these issues, this study compared comprehension rates for abbreviations for commonly used short- and long-acting medications and examined whether alternative labelling strategies would make medication administration safer.

\section{METHODS}

This 2-phase evaluation was undertaken after successful completion of the Alberta Research Ethics Community Consensus Initiative screening tool, ${ }^{13}$ which was used to determine review requirements. The tool indicated that the primary focus of the investigation was quality improvement rather than research, that the study involved minimal risk, and that a full ethics review was not warranted.

\section{Phase 1: Testing Comprehension of Abbreviations}

Misunderstood abbreviations have been identified as one of the underlying causes of serious, and sometimes fatal, medication errors. ${ }^{14}$ The ability to interpret abbreviations that denote whether a medication is long- or short-acting is critical when selecting and administering medications. In this study, interpretability was evaluated by testing the comprehension of various commonly used abbreviations for short- and longacting medications.

The American National Standards Institute (ANSI) has suggested that a safety symbol should be interpreted correctly by a minimum of $85 \%$ of people, with no more than $5 \%$ interpreting the symbol in a manner that would elicit either the opposite or a prohibited action. ${ }^{15}$ This benchmark was used in the study reported here to evaluate nurses' ability to correctly interpret abbreviations for short- and long-acting medications.

\section{Participants}

Nursing staff members (registered nurses [RNs], licensed practical nurses [LPNs], and student nurses) from 8 units at 2 urban acute care hospitals in Alberta were invited to participate in the evaluation, which was conducted over a 2 -week period.

\section{Assessment}

Nursing staff were asked to participate in a brief survey regarding potentially confusable medication labels. Those who agreed to participate were asked the following questions:

- What do the following abbreviations stand for: CR, SR, ER, and IR?

- Which of the prestated abbreviations indicate short-acting versus long-acting medications?

- What improvements would you recommend to reduce potential confusion between short-acting and long-acting medications?

The responses to all questions were recorded and later coded as correct, uncertain, or incorrect. The correct responses for the first and second questions were as follows: $\mathrm{CR}=$ controlled release (long-acting), $\mathrm{SR}=$ sustained release (long-acting), ER = extended release (long-acting), and IR = immediate release (short-acting).

\section{Phase 2: Evaluating an Alternative Labelling Strategy}

Given the confusion surrounding use of abbreviations for short- and long-acting medications, the Regional Medication Safety Reading Group recommended standardization of how these drugs are designated on all labels within the health care region, including electronic and paper medication administration records, medication labels, and medication storage bins. Before the recommendation was accepted, the following evaluation was conducted to determine its potential effectiveness. Specifically, the authors wanted to determine whether adding the word "LONG" to all labels for long-acting medications would reduce ambiguity and the potential for medication 
administration errors. There was some discussion as to whether the word "SHORT" should be added to labels for all shortacting medications. As such, this evaluation also examined if doing so would provide additional benefit.

\section{Participants}

Nursing staff members (RNs, LPNs, and student nurses) from 15 units at an urban acute care centre were invited to participate in this evaluation, which consisted of a brief survey to test various label configurations and to determine which format would be best for avoiding medication errors.

\section{Assessment}

Each participant was shown a screen shot from an electronic medication administration record, with an order for oxycodone $5 \mathrm{mg}$ circled in red, along with a photograph of an oxycodone CR 5-mg blister pack. This pairing represents a mismatch between the drug order (short-acting) and the medication supplied (long-acting). The following instructions were provided: "The upper picture displays an order for oxycodone. Would it be appropriate to administer the medication illustrated in the lower picture based on the information highlighted in the picture above?" Three combinations of screen shot and medication label were created, differing only in the presentation of the drug name in the electronic medication administration record and on the medication label (see Table 1 for a summary of the differences and see Appendices 1, 2, and 3 , available online at www.cjhp-online.ca/index.php/cjhp/issue/ view/82/showToc, for the appearance of the test materials). Each participant was shown only 1 of the 3 versions.

Responses were recorded and later coded as either correct (response to study question: no), incorrect (response: yes), near miss (initial response yes, then changed to no), or uncertain (participant expressed uncertainty or said that he/she would ask another nurse). Although the probability of occurrence might be low, the latter 3 responses could all result in medication administration errors.

\section{RESULTS}

\section{Phase 1: Testing Comprehension of Abbreviations}

A total of 36 nursing staff members (RNs, LPNs, and student nurses) participated in phase 1 of the study. On average, participants had been nursing for 6.6 years. All of the participants were involved in medication administration, but student nurses $(n=2)$ could administer medications only under the supervision of an RN or LPN.

Ten $(28 \%)$ of the nursing staff correctly identified all of the tested abbreviations, and 14 (39\%) correctly classified all abbreviations as to whether they denoted short- or long-acting medications (Table 2). The only abbreviation that met the ANSI benchmark was CR, for which $92 \%$ provided the correct classification and $0 \%$ provided the incorrect classification. Eight $(22 \%)$ of the nursing staff incorrectly classified the abbreviation ER as denoting a short-acting medication, and 2 $(6 \%)$ incorrectly classified the abbreviation SR as denoting a short-acting medication.

Nursing staff suggested several strategies to mitigate potential confusion and to enhance the comprehension of abbreviations, including writing out the full name on all labels, explicitly indicating whether a product is short- or long-acting, using consistent abbreviations, adding brightly coloured auxiliary labels, placing reference materials near medication storage areas, and purchasing medications with distinct packaging, to avoid problems with look-alike products.

\section{Phase 2: Evaluating an Alternative Labelling Strategy}

A total of 68 nursing staff members (RNs, LPNs, and student nurses) participated in phase 2 of the study. On average, participants had been nursing for 9.2 years. All of the participants were involved in administering medications, including narcotics, but the student nurses $(n=6)$ could administer narcotics only under the supervision of an RN or LPN.

Label formatting affected the likelihood of a potential medication administration error $(F[2,65]=6.917, p=0.002)$ (Table 3). Specifically, there were fewer responses that could potentially lead to an error when both "SHORT" and "LONG" were explicitly indicated (version A; $9 \%$ potential error rate; $n=2$ ) or when "LONG" was indicated on the medication label (version B; $23 \%$ potential error rate; $n=5$ ) than when neither "SHORT" nor "LONG" was explicitly indicated (version C; $54 \%$ potential error rate; $n=13)(t[44]=$ $3.63, p<0.001 ; t[44]=2.25, p=0.015$, respectively). However, including "SHORT" in the medication administration record to designate a short-acting medication, in addition to including "LONG" on the medication label for a long-acting medication, did not significantly reduce potential errors $(t[42]=1.22$, $p=0.11$ ).

The frequency of incorrect responses and near misses did not differ significantly regardless of whether "SHORT" was added to the medication administration record and/or "LONG" was added to the medication label $(F[2,65]=0.19$, $p=0.83 ; F[2,65]=0.93, p=0.40$, respectively). There were, however, significant differences in the number of nursing staff who were uncertain if it was appropriate to administer the medication $(F[2,65]=6.59, p=0.002)$. Specifically, when viewing labels with nothing added (version C; see Appendix 3, available online at www.cjhp-online.ca/index.php/cjhp/issue/ view/82/show Toc), 9 (38\%) of the nursing staff were unable to determine if it was appropriate to administer "oxycodone CR" 
Table 1. Labelling for Short- and Long-Acting Oxycodone in Medication Administration Record and on Medication Label

\begin{tabular}{|c|c|c|c|}
\hline \multirow[b]{2}{*}{ Item } & \multicolumn{3}{|c|}{ Version; Wording Used } \\
\hline & Version $A^{*}$ & Version Bt & Version C $¥$ \\
\hline $\begin{array}{l}\text { Electronic medication } \\
\text { administration record }\end{array}$ & oxycodone (SHORT) & oxycodone & oxycodone \\
\hline Medication label & oxycodone CR (LONG) & oxycodone CR (LONG) & oxycodone CR \\
\hline
\end{tabular}

Table 2. Comprehension Rates for Abbreviations for Short- and Long-Acting Medications Tested

\begin{tabular}{|c|c|c|c|c|c|c|c|c|}
\hline \multirow{3}{*}{$\begin{array}{l}\text { Abbreviation } \\
\mathrm{CR}\end{array}$} & \multicolumn{8}{|c|}{ Result; No. (\%) of Participants } \\
\hline & \multicolumn{2}{|c|}{$\begin{array}{c}\text { Correct } \\
\text { Definition }\end{array}$} & \multicolumn{2}{|c|}{$\begin{array}{c}\text { Correct } \\
\text { Classification }\end{array}$} & \multicolumn{2}{|c|}{$\begin{array}{l}\text { Uncertain about } \\
\text { Classification }\end{array}$} & \multicolumn{2}{|c|}{$\begin{array}{c}\text { Incorrect } \\
\text { Classification* }\end{array}$} \\
\hline & 29 & (81) & 33 & $(92)$ & 3 & (8) & 0 & (0) \\
\hline SR & 17 & $(47)$ & 26 & $(72)$ & 8 & $(22)$ & 2 & (6) \\
\hline ER & 18 & $(50)$ & 17 & (47) & 11 & (31) & 8 & $(22)$ \\
\hline IR & 15 & $(42)$ & 23 & (64) & 13 & (36) & 0 & $(0)$ \\
\hline Mean & 19.75 & (55) & 24.75 & (69) & 8.75 & (24) & 2.5 & (7) \\
\hline All & 10 & $(28)$ & 14 & (39) & 1 & (3) & 0 & (0) \\
\hline
\end{tabular}

$\mathrm{CR}=$ controlled release, $\mathrm{SR}=$ sustained release, $\mathrm{ER}=$ extended release, $\mathrm{IR}=$ immediate release.

*With an incorrect classification, the abbreviation was understood to mean exactly the opposite of its actual meaning.

Table 3. Potential Medication Errors Based on Responses during Simulation Exercise

\begin{tabular}{|c|c|c|c|c|c|c|}
\hline \multirow[t]{2}{*}{ Version } & \multirow[t]{2}{*}{$n$} & \multirow{2}{*}{$\begin{array}{c}\text { Mean Experience } \\
\text { (years) }\end{array}$} & \multicolumn{4}{|c|}{ Response; No. (\%) of Participants } \\
\hline & & & Correct & Incorrect & Near Miss & Uncertain \\
\hline$\overline{A^{*}}$ & 22 & 11.55 & $20(91)$ & $1 \quad(5)$ & $1 \quad(5)$ & $0 \quad(0)$ \\
\hline $\mathrm{B}+$ & 22 & 8.84 & $17(77)$ & 2 (9) & $0 \quad(0)$ & $3(14)$ \\
\hline$C \neq$ & 24 & 7.26 & $11(46)$ & 2 (8) & $2 \quad(8)$ & $9(38)$ \\
\hline
\end{tabular}

*SHORT and LONG indicated in medication administration record and on medication label, respectively; see Appendix 1; all appendices are available at www.cjhp-online.ca/index.php/cjhp/issue/view/82/showToc +LONG indicated on medication label; see Appendix 2.

¥Type of formulation not explicitly indicated; see Appendix 3.

when "oxycodone" was ordered. When "LONG" was added to the medication label for the long-acting formulation (version B; see Appendix 2), significantly fewer nursing staff were uncertain (3 [14\%]; $t[42]=-1.82, p=0.038)$. Adding the designation "SHORT" to the order in the medication administration record, in addition to adding "LONG" to the medication label (version A; see Appendix 1), further reduced the number of nursing staff who were uncertain to $0 \%(t[42]=-1.87$, $p=0.034)$.

\section{DISCUSSION}

This study has clearly shown that abbreviations currently used by manufacturers to differentiate short- and long-acting medications are problematic. Furthermore, it has highlighted the potential consequences of using non-intuitive abbreviations to differentiate medications with different release rates.
Most abbreviations currently used to indicate short- versus long-acting medications were not correctly understood by many of the nursing staff in this study. Of more concern was the number of nursing staff who interpreted "ER" as indicating a short-acting medication. This is probably because the letter $\mathrm{E}$ in the hospital setting typically refers to "emergency" (e.g., "ER" for emergency room and "ED" for emergency department). Furthermore, storage containers for pentobarbital and phenobarbital on one pediatric unit at one hospital participating in this study were labelled "Emergency Release". This labelling reminds staff to complete specific paperwork associated with these medications, in accordance with the Special Access Programme of Health Canada, which might have led some nursing staff to think that ER stood for "emergency release". An effort to clarify and standardize the communication of different release rates is needed to minimize confusion and, ultimately, to minimize errors in selecting and administering medications. 
Adding "SHORT" to the medication administration record or "LONG" to the medication label for oxycodone CR resulted in more accurate communication of the release rate and reduced the probability of a medication error among nursing staff engaged in the simulated medication administration exercise. The abbreviation found in phase 1 of the study to be the most intuitive (CR) was used to indicate the long-acting medication in phase 2. As such, the potential benefits of modified labelling are likely to be of greater magnitude for abbreviations that were more frequently misunderstood (e.g., ER, SR).

The findings from phases 1 and 2 of this evaluation were presented to the Pharmacy Clinical Safety Committee and the Regional Medication Safety Reading Group. The testing materials were also brought to these meetings to demonstrate both the study method and the realism of the testing materials. Together, these bodies decided to change the formatting of labels for narcotics that are available in both short- and longacting formulations to include the term "SHORT acting" or "LONG acting" as appropriate. This change was applied to the pharmacy computer systems, narcotic packaging produced in house, and narcotic count sheets. Although only the terms "SHORT" and "LONG" were tested and the implemented solution also includes the word "acting", the Pharmacy Clinical Safety Committee and the Regional Medication Safety Reading Group thought that this additional word would further clarify the difference. A business case was developed to add "SHORT acting" or "LONG acting" to the electronic and paper medication administration records and was submitted to the Information Technology and Pharmacy departments. The business case included a summary of local adverse events involving mix-ups between short- and long-acting medications, as well as the findings from this evaluation, which highlighted the fact that the proposed recommendations were evidencebased and would likely improve patient safety. Consequently, changes were made to electronic medication administration records (in the administration instructions), as well as to paper medication administration records at acute care sites without electronic systems (in the notes field).

Additional strategies have been implemented to facilitate medication safety for short- and long-acting narcotics. Although the incremental effectiveness of these strategies has not been evaluated, they are consistent with the recommendations of external agencies related to the labelling of narcotics. ${ }^{11,14}$ These additional strategies include adding auxiliary labels to storage locations and medication packaging, physically separating short- from long-acting narcotics (i.e., placement in different sections in narcotic cupboards), and grouping short- and longacting narcotics on narcotic count sheets. The new auxiliary labels are either white with black type (for "SHORT acting") or black with white type (for "LONG acting") and have been consistently applied to all narcotic storage bins. Each narcotic and strength of each specific narcotic is stored in its own bin. The auxiliary labels visibly differentiate the 2 sections in the narcotic cupboards and likely enhance awareness among health care staff who stock or select narcotics. Furthermore, the same auxiliary labels have been applied to commercially packaged narcotics and narcotics packaged in house that are available in both short- and long-acting formulations, for consistent communication of this difference for any product not in the storage bin (i.e., in the pharmacy, during transport, and during medication preparation). The narcotic count sheets have been changed to ensure consistency in organization of narcotics between the cupboard and the sheet, to facilitate counts. All safety improvements were communicated to health care staff through a medication posting.

\section{CONCLUSIONS}

This study has demonstrated how evidence-based research at the local level, along with feedback and input from front-line staff, can be used to address longstanding problems. Although no strategy can eliminate all errors involving medications with different release rates, this study generated evidence-based solutions that were subsequently implemented to minimize potential errors through more intuitive labelling of medications. The findings from this evaluation are applicable to other organizations seeking to reduce the risk of errors related to medication abbreviations and should also be considered by pharmaceutical companies. Other abbreviations that may not be intuitive should be evaluated by means of similar methodologies.

\section{References}

1. Common medication pairs that contribute to wrong drug errors. PAPSRS Patient Saf Advis 2007 [cited 2011 Aug 2];4(3):1-2. Available from: www.patientsafetyauthority.org/ADVISORIES/AdvisoryLibrary/2007/ sep4(3)/documents/89.pdf

2. FDA and the pharmaceutical industry must be more responsive for a safer healthcare system. ISMP Med Safe Alert 2004 Nov 4 [cited 2011 Jul 25]. Available from: www.ismp.org/newsletters/acutecare/articles/20041104.asp

3. Paparella S. What's in a name? The trouble with brand name extensions and suffixes. J Emerg Nurs 2006;32(3):263-266.

4. ISMP action agenda: July-September, 1998. ISMP Med Safe Alert 1998 Jan 27 [cited 2011 Jul 25]. Available from: www.ismp.org/Newsletters/ acutecare/articles/A4Q98Action.asp

5. Continuing mix-ups reported between OxyContin (oxycodone $\mathrm{HCl}$ controlled-release tablets) and oxycodone $\mathrm{HCl}$ immediate release tablets. ISMP Med Safe Alert 2001;6(17).

6. Worth repeating XL, SR, ER, CD, L . . confused? So are we! ISMP Med Safe Alert 2003;8(21):3.

7. Various release formulations of oral opioids cause confusion. ISMP Nurse Advise ERR 2009;7(3):1-2.

8. Safeguard against errors with long-acting oral narcotics. ISMP Can Saf Bull 2003 [cited 2011 Jul 19];3(9):1-2. Available from: www.ismpcanada.org/download/safetyBulletins/ISMPCSB2003-09Narcotics.pdf

9. Prograf and Advagraf mix-up. ISMP Can SafBull 2009 [cited 2011 Jul 19]; 9(5):1-2. Available from: www.ismp-canada.org/download/safetyBulletins/ ISMPCSB2009-5-PrografandAdvagrafMix-up.pdf 
10. Drug name suffix confusion is a common source of errors. PA-PSRS Patient Saf Advis 2004 [cited 2011 Aug 2];1(4):17-18. Available from: www.patientsafetyauthority.org/ADVISORIES/AdvisoryLibrary/2004/ $\operatorname{dec} 1$ (4)/Documents/17.pdf

11. Gaunt MJ. Preventing oxycodone mix-ups. Pharm Times 2007 Jun 1 [cited 2011 Jul 25]. Available from: www.pharmacytimes.com/ publications/issue/2007/2007-06/2007-06-6581

12. Be on the lookout for oxycodone mix-ups. Pa State Board Pharm [newsletter] 2006/2007 Winter;:3-4. Available from: www.portal.state.pa.us/portal/ server.pt/community/pharmacy/19131/newsletter_archive/830235

13. ARECCI ethics screening tool [online tool]. Alberta Research Ethics Community Consensus Initiative (ARECCI) Network; 2005 [revised 2008, cited 2008 Apr 16]. Available from: www.ahfmr.ab.ca/arecci/ screening/

14. Shared learning - reported incidents involving hydromorphone. ISMP Can Saf Bull 2006 [cited 2011 Aug 2];6(9):1-3. Available from: www.ismp-canada.org/download/safetyBulletins/ISMPCSB200609Hydromorphone.pdf

15. American national standard for criteria for safety symbols. ANSI Z535.3. New York (NY): American National Standards Institute; 2002.
Jonas Shultz, MSc, is with Patient Safety, Alberta Health Services, Calgary, Alberta.

Lisa Strosher, MSc, is with Patient Safety, Alberta Health Services, Calgary, Alberta.

Shaheen Nenshi Nathoo, BSCPharm, ACPR, is with Pharmacy, Alberta Health Services, Calgary, Alberta.

Jim Manley, BPE, is with Pharmacy, Alberta Health Services, Calgary, Alberta.

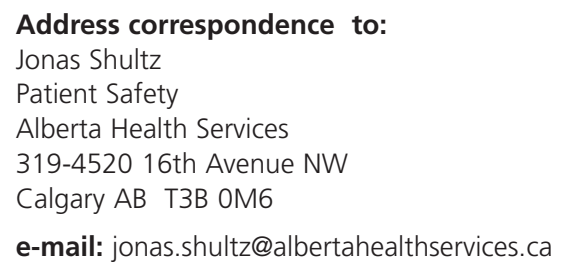

\section{Acknowledgements}

The authors greatly appreciate the contributions of all those involved in various aspects of this evaluation, including the Pharmacy Clinical Safety Committee, members of the Regional Medication Safety Reading Group, the Patient Care Information System team, and the nursing staff members.

\section{CJHP Subscriptions 20 I I / Abonnements au JCPH 20 I I}

CSHP has introduced both Print and Print + Online pricing models for CJHP subscriptions. Print + Online $\mathrm{CJHP}$ is included as a benefit of CSHP membership. All prices are in Canadian funds.

La SCPH a établi une grille tarifaire pour l'abonnement à la copie imprimée du JCPH seulement et pour l'abonnement à la fois aux copies imprimée et électronique du journal. L'abonnement combiné est inclus dans les droits d'adhésion à la SCPH. Tous les prix sont en dollars canadiens.

\begin{tabular}{|l|l|l|}
\hline $\begin{array}{l}\text { Subscriber group / Groupe } \\
\text { d'abonnés }\end{array}$ & $\begin{array}{l}\text { Print only / Texte imprimé } \\
\text { seulement }\end{array}$ & $\begin{array}{l}\text { New! Print + Online copy } \\
\text { Nouveau! Texte imprimé } \\
\text { et exemplaire électronique }\end{array}$ \\
\hline $\begin{array}{l}\text { Nonmembers within Canada / } \\
\text { Non-membres au Canada }\end{array}$ & $\begin{array}{l}\$ 110.00 \text { per year, plus GST or HST } \\
110,00 \$ \text { par an, plus TPS ou TVH }\end{array}$ & $\begin{array}{l}\$ 150.00 \text { per year, plus GST or HST } \\
150,00 \$ \text { par an, plus TPS ou TVH }\end{array}$ \\
\hline USA / É.-U. & $\begin{array}{l}\$ 140.00 \text { per year } \\
140,00 \$ \text { par an }\end{array}$ & $\begin{array}{l}\$ 180.00 \text { per year } \\
180,00 \$ \text { par an }\end{array}$ \\
\hline Foreign / Étranger & $\$ 180.00$ per year & $\$ 220.00$ per year \\
& $180,00 \$$ par an & $220,00 \$$ par an \\
\hline
\end{tabular}

More details can be found at www.cjhp-online.ca. If you would like to purchase a subscription, please fill out our CJHP 2011 Subscription Application Form, which can be found on the CJPH website. Please direct any comments or questions to Colleen Drake, Publications Administrator, at cdrake@cshp.ca.

Des détails supplémentaires sont fournis à www.cihp-online.ca. Si vous désirez vous abonner, veuillez remplir le formulaire d'abonnement au JCPH 2011. Vous pouvez l'obtenir en visitant le site Web du JCPH. Pour tout commentaire ou toute question, veuillez vous adresser à Colleen Drake, agente des publications, en écrivant à cdrake@cshp.ca. 